\title{
THE HEALTH AND WELFARE OF AUSTRALIA'S ABORIGINAL AND TORRES STRAIT ISLANDER PEOPLES 1999
}

\section{Joan Cunningham \\ Epidemiologist, National Centre for Aboriginal and Torres Strait Islander Statistics \\ Australian Bureau of Statistics, Darwin}

The publication The Health and Welfare of Australia's Aboriginal and Torres Strait Islander Peoples 1999 is the second edition in this two-yearly series of reports that provide a comprehensive statistical overview of the health and welfare of indigenous people. While the focus of the publication is mainly national, state comparisons have been included where possible. In addition, information has been incorporated about community-initiated programs that seem to be having a positive effect on health at the local level.

The report covers a range of topics including:

- aspects of the demographic, social and economic context of health and wellbeing

- the use of welfare and community services

- risk factors for health

- health service issues

- the morbidity and mortality of indigenous Australians.

A special chapter on kidney disease is also included in this edition. It explores such issues as the incidence and prevalence of kidney failure, hospitalisation and mortality due to kidney disease, and quality of life for patients with kidney disease.
The availability of data and the ability to monitor trends over time continue to be limited by:

- the quality of the identification of indigenous people in administrative data collections (for example, in hospital separations and death records)

- uncertainties in estimating the indigenous population

- the quality of some types of survey data.

A number of recent initiatives have ensured that progress is being made in these areas, and these initiatives are described in the report. $\boldsymbol{H}^{\mathrm{N}}$

Copies of The Health and Welfare of Australia's Aboriginal and Torres Strait Islander Peoples 1999 are available from all Australian Bureau of Statistics bookshops. Publication summaries are also available through the bookshops. A copy of the executive summary is available on the Australian Bureau of Statistics Web site at www.abs.gov.au. For further information about the contents of the publication, contact Dr Joan Cunningham by telephone: (08) 89432165 , or by email at joan.cunningham@abs.gov.au. For more information about statistics on Australia's Aboriginal and Torres Strait Islander population, contact the National Centre for Aboriginal and Torres Strait Islander Statistics on (08) 89432190 or freecall 1800633216 (outside Darwin).

\section{PUBLIC HEALTH IN NSW FROM THIS DECADE TO 2010}

continued from page 162

funds to address these, for example, in aboriginal health, and drug and alcohol. However, we recognise that the Public Health Officer Training Program alone will not address all our public health training needs.

We have identified a need for more flexible training arrangements to upskill public health workers in rural and remote areas. We will need to further review our capacity to meet such challenges of the next decade as environmental change, mental health promotion, and changes in food regulation, and to tailor our training to meet those needs.

Combined with the education and training initiatives funded through the Commonwealth Public Health Education and Research Program, there has been an unprecedented growth in the public health workforce. Over the decade, public health education and training opportunities have gone from a two-course meal to a smorgasbord. There is a broad range of public health training opportunities on offer throughout the State and this continues to expand. The down side of this may be that resources for education and training are spread thinly. In the new year, we propose to meet with providers of public health education to start examining the match between training needs and capacity in NSW. Equally important for the development of public health, we will look at ways to strengthen the links between research and practice. In doing so, we will be seeking to improve the evidence base of public health practice, including our understanding of the range and relative importance of hazards, the range and relative effectiveness of interventions, and the relative merits of those interventions in terms of reducing health inequities.

So, entering the next decade, I remain enthusiastic about working in public health and about what we can achieve. There is still plenty of scope for innovation, improvement and, through action, health gain. Roll on the next challenge! $\$$ 